Abstracta Iranica Abstracta Iranica

Revue bibliographique pour le domaine irano-aryen

Volume 32-33 | 2013

Comptes rendus des publications de 2009-2010

\title{
Ali Anooshahr. The Ghazi Sultans and the Frontiers of Islam. A comparative study of the late medieval and early modern periods
}

\section{Corine Lefèvre}

\section{(2) OpenEdition \\ 1 Journals}

\section{Édition électronique}

URL : http://journals.openedition.org/abstractairanica/40595

DOI : 10.4000/abstractairanica.40595

ISSN : 1961-960X

Éditeur :

CNRS (UMR 7528 Mondes iraniens et indiens), Éditions de l'IFRI

\section{Édition imprimée}

Date de publication : 1 décembre 2013

ISSN : 0240-8910

\section{Référence électronique}

Corine Lefèvre, "Ali Anooshahr. The Ghazi Sultans and the Frontiers of Islam. A comparative study of the late medieval and early modern periods », Abstracta Iranica [En ligne], Volume 32-33 | 2013, document 220, mis en ligne le 01 juillet 2016, consulté le 28 septembre 2020. URL : http://

journals.openedition.org/abstractairanica/40595; DOI : https://doi.org/10.4000/abstractairanica. 40595

Ce document a été généré automatiquement le 28 septembre 2020.

Tous droits réservés 


\title{
Ali Anooshahr. The Ghazi Sultans and the Frontiers of Islam. A comparative study of the late medieval and early modern periods
}

\author{
Corine Lefèvre
}

\section{RÉFÉRENCE}

Ali Anooshahr. The Ghazi Sultans and the Frontiers of Islam. A comparative study of the late medieval and early modern periods. Londres \& New York, Routledge, 2009, 208 p.

1 Comme l'indique l'A. dans son introduction, cet ouvrage n'est pas une histoire du ghazā (raid pour la foi islamique) dans les sociétés islamiques prémodernes mais une réflexion sur la figure du sultan ghāzì (guerrier combattant pour la foi islamique) et sur la fortune exceptionnelle qu'elle connut auprès des princes musulmans établis aux frontières du monde islamique (des Balkans à l'Inde en passant par l'Anatolie) entre le $\mathrm{XI}^{\mathrm{e}}$ et le $\mathrm{XVI}^{\mathrm{e}}$ siècle. Son objectif principal est ainsi de reconstituer les processus de formation, de transmission et d'imitation de cette image magnétique du roi ghāzī.

2 Les Mémoires du premier Moghol Bābur (r. 1526-1530) et l'appropriation par ce dernier du modèle ghāzī constituent le point de départ de l'analyse. Ce choix est important pour deux raisons. D'une part, il permet à l'A. d'identifier les deux figures historiques et littéraires - Mahmūd de Ghazni (r. 998-1030) et l'Ottoman Murād II (r. 1421-1444 puis 1446-1451) - à l'origine de cette appropriation et, ce faisant, de définir les trois principaux pôles de circulation du paradigme du sultan ghāzi autour desquels s'organise son étude : les Ghaznavides du XI ${ }^{e}$ s., les Ottomans du XV ${ }^{e}$ s. et les premiers Moghols. De ce point de vue, on regrettera cependant que l'A. n'ait pas prêté plus d'attention au rôle de Tīmūr dans la transmission du modèle ghāzī et qu'il ne fasse pas référence aux pages que Michele Bernardini a consacrées à ce sujet dans son Mémoire et 
propagande à l'époque timouride (2008). D'autre part, la nature autobiographique du Bābur-nāma conditionne l'adoption par l'A. d'une méthode d'analyse originale renversant le rapport traditionnel entre texte et hors-texte: loin d'être le reflet (plus ou moins fidèle) des actions de Bābur, ses Mémoires sont ici considérés comme un scénario de vie que le prince élabora à partir de ses lectures et qu'il se proposa de réaliser à travers ses actions. En d'autres termes, c'est la littérature qui informerait le réel, et non l'inverse. Que l'on adhère ou pas à ce postulat initial que l'A. cherche par la suite à appliquer aux autres sultans ghäzīs et aux textes qu'ils commanditèrent, l'ensemble de l'ouvrage est solidement argumenté et s'appuie sur une fine analyse croisée d'une impressionnante variété de sources rédigées en turc, persan et arabe, certaines bien connues (comme le Siyāsat-nāma de Niẓām al-Mulk) d'autres ignorées même des spécialistes.

3 Le premier chapitre retrace donc la façon dont Bābur s'identifia à la figure du sultan ghāzì à son entrée en Afghanistan et, plus encore, en Inde en décrivant ses actions suivant une trame narrative similaire à celle des ghazās menés par Mahmūd de Ghazni et Murād II - dont les récits lui étaient parvenus par l'intermédiaire de textes tels que le Kitāb al-Yaminī (1021) de 'Utbī et, plus hypothétiquement, les Ghazās de sulțān Murād (milieu du XV $\mathrm{XV}^{\mathrm{e}}$ s.). Comme le montre le deuxième chapitre, l'identification de Bābur à la figure du ghāzì dans la section indienne du Bābur Nāma marque une rupture forte par rapport aux sections centre-asiatique et afghane où son prestigieux ancêtre Tīmūr (1336-1405) constituait la référence légitimante majeure. L'abandon de Tīmūr comme modèle s'explique essentiellement par la nécessité pour Bābur de rallier à sa cause les musulmans de l'Inde afin d'y pérenniser ses conquêtes. Conscient de ce que l'héritage de Tīmūr, en particulier sa mise à sac de Delhi en 1398, constituait un lourd handicap dans le sous-continent, Bābur s'appropria le «masque du roi ghāzī» qui lui permit simultanément de s'inscrire dans la sphère de l'orthodoxie sunnite chère aux šayHzādas et de se laver auprès de ces derniers des soupçons de shiisme provoqués par son alliance avec le Safavide Ismā̄îl I ${ }^{\text {er }}$ (r. 1501-1524). Cette stratégie, héritée pour bonne part de la longue tradition tīmūride de manipulation de l'image royale, s'avéra payante - tout au moins à en croire les éléments rassemblés par l'A. témoignant de sa réception plutôt positive auprès des musulmans indiens.

4 Les deux chapitres suivants $(3 \& 4)$ opèrent un retour en arrière vers la dynastie matrice de la figure du sultan ghāzī que Bābur reprendrait avidement à son compte cinq siècles plus tard : les Ghaznavides. Le troisième chapitre met en lumière le rôle pionner que Mahmūd joua dans ce domaine : à l'inverse de ce qui prévalait à l'époque de ses prédécesseurs $\mathrm{du} \mathrm{X}^{\mathrm{e}} \mathrm{s}$., c'est en effet sous son règne que les confrontations des Ghaznavides avec les non-musulmans commencèrent à être dépeintes, non plus comme un jihad défensif visant à sauver l'islam d'une menace imminente, mais comme des opérations agressives menées par un sultan ghāzī aux allures de héros épique. Insérés dans les chroniques et panégyriques officiels, les récits de ces ghazās suivaient largement le schéma narratif des lettres ou proclamations de victoire envoyées par Mahmūd depuis le front indien, ce qui explique leur uniformité et leur caractère stéréotypé mais aussi les modèles qui les sous-tendent : Moïse, Alexandre le Grand et Farīdūn, roi légendaire de l'ancienne tradition iranienne. Ici encore, la volonté de Mahmūd de se présenter comme un ghāzī et de modeler son comportement et son image sur ceux des héros des temps anciens s'explique par la nécessité d'établir une légitimité. Cependant, comme le montre le chapitre 4, l'image grandiose du roi ghāzì élaborée par Mahmūd et ses historiographes n'était pas la seule à avoir cours sous les 
Ghaznavides, et elle fut concurrencée, sous la plume des chroniqueurs plus tardifs tels que Bayhaqī (m.1077), par la figure beaucoup plus modeste de l'austère guerrier combattant avec ses frères d'armes pour la foi islamique et bientôt assimilé au « roi fondateur ». C'est Sebüktigin (m. 997), le père de Mahmūa, qui fut investi de cette nouvelle identité.

Dans le chapitre 5, l'A. concentre son attention sur la dualité de l'image royale qui résulta de l'émergence de cette autre figure du ghāzī et l'explique par la bureaucratisation croissante des sultanats ghaznavide et seldjoukide. Aux yeux des administrateurs-chroniqueurs, le rôle du souverain était désormais d'assurer l'ordre et la prospérité du royaume et non plus de mener des raids contre les non-musulmans une tâche qui devait être laissée aux subordonnés postés aux frontières. C'est dans ce contexte que le ghazā fut relégué aux premiers temps de la dynastie. L'A. examine ensuite la transformation de ce modèle dual en un modèle tripartite et cyclique des images royales, un processus dans lequel Niẓām al-Mulk joua un rôle particulièrement important. C'est lui en effet qui formalisa le schéma cyclique encore implicite chez Bayhaqī, et résuma l'histoire de la dynastie à une succession d'étapes dont chacune était incarnée par un monarque idéalisé : la première est celle du roi fondateur, ghāzì humble et accessible (Sebüktigin) ; la seconde est une période d'apogée et de maturité durant laquelle un roi majestueux administre avec justice son royaume et supervise l'action des ghāzis qui lui sont subordonnés (Mahmūd); la troisième correspond au déclin, engendré par un souverain débauché et incapable (Mas'ūd, r. 1030-1041). Le chapitre se termine sur un détour par l'historiographie des derniers šāhs du Khwarezm et des Seldjoukides d'Anatolie, dont l'analyse fait apparaître une redéfinition spécifiquement anti-mongole du ghazā ainsi que, dans le cas anatolien, l'appropriation du principe de la « triade des rois » pour retracer l'histoire des Seldjoukides de Rūm.

C'est précisément vers Rūm que se tournent les deux derniers chapitres (6 et 7), dont l'objet central est le redéploiement progressif de la figure du sultan ghāzī chez les Ottomans du XV s. - autre modèle identifié par l'A. pour Bābur. Le chapitre 6 retrace d'abord cette réémergence à partir de la correspondance échangée entre Tīmūr et Bāyezīd I ${ }^{\text {er }}$ (r. 1389-1402) dans les années précédant la bataille d'Ankara, le premier s'y présentant comme le ghāzi des ghāzis (i.e. des Ottomans), le second reprenant à son compte la tradition anatolienne du ghazā contre les Mongols païens (auxquels Tīmūr est implicitement assimilé). C'est cependant la défaite de Bāyezīd en 1402 et la crise de légitimité qui s'ensuivit qui constitua le tournant majeur. Afin de contrer l'idée selon laquelle la débâcle d'Ankara marquait la phase finale du cycle dynastique ottoman, les successeurs de Bāyezīd cherchèrent à se présenter comme les initiateurs d'un nouveau cycle en se rapprochant au plus près de la figure du roi fondateur ghāzí. Comme le montre le chapitre 7, c'est à Murād II qu'il revint d'accomplir cette transformation. Pour ce faire, il construisit une image du ghāzī puisant simultanément à la correspondance entre Tīmūrides et Ottomans et à la littérature héroïque des différentes factions du royaume (seigneurs de guerre de Roumélie, princes d'Anatolie centrale); la promotion parallèle d'une définition spécifiquement anti-chrétienne du ghazā devait assurer la cohérence et l'unification de ces éléments hétérogènes. De fait, plusieurs des projets historiographiques donnant à lire la nouvelle identité ghāzì de Murād II précédèrent de peu la grande offensive militaire qu'il lança contre la Serbie et la Hongrie à la fin des années 1430. Le chapitre se clôt sur trois histoires dynastiques ottomanes produites dans la seconde moitié $\mathrm{du} \mathrm{XV}^{\mathrm{e}} \mathrm{s}$., dont l'analyse met en lumière la 
pérennité de l'appropriation et de la reformulation par Murād II de la figure du sultan ghāzì.

\section{AUTEURS}

\section{CORINE LEFÈVRE}

CNRS, Paris 